\title{
Sense of Community and Self-Rated Health: Mediating Effect of Social Capital
}

\author{
Cheng-Neng Lai \\ Department of Public Relations and Advertising, Shih Hsin University, Taiwan \\ Email: layjn@cc.shu.edu.tw \\ Received January $5^{\text {th }}, 2013$; revised April 17 $7^{\text {th }}, 2013$; accepted May $6^{\text {th }}, 2013$
}

\begin{abstract}
Copyright (C) 2013 Cheng-Neng Lai. This is an open access article distributed under the Creative Commons Attribution License, which permits unrestricted use, distribution, and reproduction in any medium, provided the original work is properly cited.
\end{abstract}

\begin{abstract}
Individuals expect to get better well-being through the community; however the formation of causal relations is rarely mentioned. This study was conducted to test a model by examining the relationship between Sense of Community and Self-rated Health, and took Social Capital as the mediating variable. Social Capital was divided into two variables: Trust and Interaction. The method of Structural Equation Modeling was used for evaluation. The result of the analysis verified the Sense of Community's causeeffect relationship on Self-rated Health, and the mediation effect of Social Capital existed between them. The contribution of this research is to prove a positive health promotion path which is accepted by members of a community. The collective attributes of the elements of social capital, including trust and interaction in a neighborhood network are the focus.
\end{abstract}

Keywords: Sense of Community; Social Capital; Self-Rated Health; Trust; Interaction

\section{Introduction}

Sense of community is one of the most important areas of community psychology that has been developing for a long time (Sarason, 1974). A good environment and decent residents help to create a more ideal and lively community, with a sense of belongingness (Duffy et al., 1996). The establishment of a sense of community motivates the health and happiness of the community (Davidson \& Cotter, 1993), whereas a collapse of a sense of community not only reduces mental health index (Caspi et al., 2000) and increases the perception of loneliness (Prezza et al., 2001), but it also triggers a negative impact on individual health hazards (Cutrona et al., 2000). According to the research of Peterson et al. (2006), the aspect of sense of community is more significantly correlated to mental health than the physiological aspect is.

Specifically speaking, a sense of community is perceived by the residents as a sense of belongingness about the community as a whole, which motivates the residents to identify with the community and to develop the willingness to take action (McMillan \& Chavis, 1986; Wilson \& Baldassare, 1996). The purpose of a public community is to form an identity, with lively local citizens and a community which supports its citizens. The status of health is the end result (Mcknight, 2002). Pooley et al. (2005) considered a sense of community as a better way to understand the relationship and perception of the residents in a community, in addition to serving as a proper and clear theoretical foundation for the development and planning of community health. Additionally, the issues related to an evaluation of community health are not only confined to physical fitness or to the improvement of individuals, but also to the mental factors and situations inside or outside the family and community, and ought to be taken into consideration as well (WHO, 1981).
Though functional limitations may be evaluated through the interaction among individuals and the environment, the records of implicit private ailments, pains, emotions, satisfaction or happiness still can't be obtained. Consequently, measurement of self-rated health is necessary (Patrick \& Erickson, 1993). It goes without saying that self-rated health, i.e., the perception of daily living for the residents in a community, is the most necessary thing to be understood (Sundquist \& Yang, 2007).

In this paper, social capital means that an individual has a chance or is qualified to obtain resources in the community network as a member of the community. Social capital is dynamic, including the process and the mobile status of reciprocal cause and effect embedded between an individual and the community (Pooley et al., 2005; Protes, 1998), which is truly helpful for a researcher to understand the community and to add a supplement to relevant demonstrations. It should be noted that the resources acquired are not personal assets, but public goods contained in a relationship between an individual and the others. These resources not only improve living standards, enhance the quality of life in the community, but also help the physical and mental health of the residents and even help residents to overcome traumas and prevent diseases (Putnam, 2000). There are two strategies of health maintenance or promotion for the general public in the new era, in which the public is becoming aware of, which involve the medical system and the public community.

It has also been found that interaction in a neighborhood and the confidence of the residents are positive in promoting health (McMillan \& Chavis, 1986; Prezza et al., 2001). Neighborhood activities and confidence of the residents are the core issues of social capital (Putnam, 1993, 2001).

Though previous studies have indicated that a higher sense of community has resulted in better self-rated health and has 
caused a positive correlation between them (Adams, 1992; Farrell et al., 2004), still, how a sense of community is exercised to enhance the self-rated health of individuals has not yet been explained clearly. It is certain that the source of the residents' happiness is their feelings of belongingness to the community, and that they may share their feelings or mitigate pressure during the process of interaction with their neighbors to achieve individual adaptation and health (Davidson \& Cotter, 1993; Hughey et al., 1999). Accordingly, an attempt to apply an approach that has a more comprehensive theoretical integration is made, for the analysis of both sense of community and the promotion of community health. In addition to testing and evaluating the causal relationship regarding health, the mediating role played by social capital is exercised for an understanding of its impact on the self-rated health of the residents. A model is thus established for reference of strategic planning for a healthy community in the future.

\section{Method}

\section{Data Collection and Analysis}

The sampling population in this research is the $\mathrm{X}$ community located in Taiwan. In addition to considering the establishment of a model, this research also provides strategies for developing community health in the future. Consequently, it is also necessary to conduct a small-scale regional study at the beginning of model establishment so as to avoid confusion caused by the social capital theory and the analysis measurements (Yan, 2006). The advantage of a small area of research is to focus on the establishment of a model instead of on the generalization of the whole area (Ullman, 2001). Interference of variables like geographical factors, environmental background, and crime rate in each community can be prevented (Farrell et al., 2004). Furthermore, to ensure the reliability and validity of this study, the population is defined as the residents over 18 years of age in $\mathrm{X}$ community. According to the statistical data, there were 1558 families, with 4539 people, in X community. Structural Equation Modeling (SEM) was adopted in this research for data analysis and for an exploration of the causal relationship among variables. SEM is a module analysis approach, and is suitable for testing complicated theories, evaluating the appropriateness of a model, analyzing the mediating effect, and comparing samples of groups (Ullman, 2001). Model operation has been conducted with LISREL8.50, and the parameters have been estimated by the Maximum Likelihood Estimation (MLE). As each research model is over-identified, there won't be any problem with parameter estimation, and a suitable model can be located more easily (Davis, 1993; Reilly, 1995; Rigdon, 1955). The sample size must be between 100 and 150, at least for MLE (Ding et al., 1995). The MLE results in a more sensitive model when the sample size increases, therefore, the sample size should not exceed 400 (Marsh et al., 1988; Tanaka, 1987). Proportional sampling was conducted. One out of every seven families was interviewed and residents over 18 were asked to fill in the questionnaire in their presence. There were 220 copies of the questionnaire issued, 213 copies recalled, and 208 were validated.

\section{Research Framework and Questionnaire Design}

The purpose of this research is to investigate the causal relationship between Sense of Community and Self-rated Health under the mediating effect of Social Capital. As the definition of social capital is diversified (Protes, 1998), two dimensions of social capital are defined in this research. The first refers to the social network (interaction among residents) and the other refers to trust. The questionnaire has been divided into three parts: Sense of Community, Social Capital and Self-rated Health. The framework and hypotheses among dimensions are illustrated in Figure 1.

The Likert 5-point scale is adopted: 1-Strongly Disagree, 3-Neutral and 5-Strongly Agree. There are three questions for the part related to Sense of Community in the questionnaire, including recognition and understanding of the importance of the community, willingness of introducing the community to others, and knowing the location of each household in the community (McMillan \& Chavis, 1986; Prezza \& Costantini, 1998). The part related to Social Capital is divided into two dimensions, which are Trust and Interaction. There are three questions for Trust, including: friendly residents, mutual caring and the sharing of resources (Putnam, 2001; Onyx \& Bullen, 2000). Three questions for the section related to Interaction are asked, including: assistance in caring for the sick people in the community, active mediation against disputes among residents, and invitation of festivities (Onyx \& Bullen, 2000; Putnam, 1993). For the part related to Self-rated Health, the three questions are: satisfaction with the physical and mental conditions of individuals, satisfaction at the daily life, and the fulfillment of physical and mental requirements in the daily life (Kawachi et al., 1999).

\section{Results}

\section{Profile of Respondents}

There are 208 valid samples in this research and their profiles are listed in Table 1. The number of females (55.8\%) is greater than that of males $(44.2 \%)$, and most of them are married $(74.5 \%)$. For age group, people from 46 to 55 account for the majority (42.3\%) and people from 36 to 45 occupy $20.2 \%$. Most of them have lived in the community for over 15 years $(58.2 \%)$, only $2.4 \%$ of them have lived there less than a year, and $9.1 \%$ of them have lived there for 1 to 5 years. As for their educational background, most of them had graduated from senior high schools or vocational schools (45.2\%), and $38.9 \%$ of them had received a college or university degree.

\section{Variables of Reliability and Validity}

The individual item of reliability in the questionnaire measures the factor loading of a latent variable for statistical significance. As the factor loading of each individual item in this research is between 0.66 and 0.85 , the suggested value of above 0.5 is met (Hair et al., 1998). As for the composite reliability

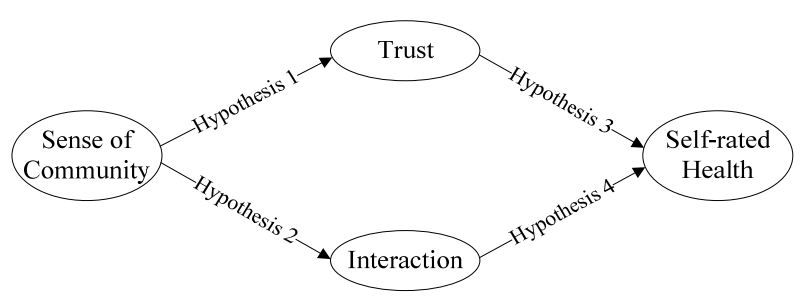

Figure 1.

Framework and hypotheses. 
Table 1.

Profile of respondents.

\begin{tabular}{|c|c|c|c|}
\hline Demographics & Category & $\begin{array}{l}\text { Sample } \\
\text { Size }\end{array}$ & $\begin{array}{c}\text { Ratio of } \\
\text { Distribution }\end{array}$ \\
\hline \multirow{2}{*}{ Gender } & Male & 92 & $44.2 \%$ \\
\hline & Female & 116 & $55.8 \%$ \\
\hline \multirow{4}{*}{ Marital Status } & Single & 41 & $19.7 \%$ \\
\hline & $\begin{array}{l}\text { Married or } \\
\text { Cohabited }\end{array}$ & 155 & $74.5 \%$ \\
\hline & $\begin{array}{l}\text { Divorced or } \\
\text { Separated }\end{array}$ & 7 & $3.4 \%$ \\
\hline & Widowed & 5 & $2.4 \%$ \\
\hline \multirow{6}{*}{ Age } & $18-25$ & 21 & $10.1 \%$ \\
\hline & $26-35$ & 34 & $16.3 \%$ \\
\hline & $36-45$ & 42 & $20.2 \%$ \\
\hline & $46-55$ & 88 & $42.3 \%$ \\
\hline & $56-65$ & 20 & $9.6 \%$ \\
\hline & Over 66 & 3 & $1.4 \%$ \\
\hline \multirow{5}{*}{$\begin{array}{l}\text { Duration of } \\
\text { Living in the } \\
\text { Community }\end{array}$} & Less than 1 year & 5 & $2.4 \%$ \\
\hline & $1-5$ years & 19 & $9.1 \%$ \\
\hline & $6-10$ years & 22 & $10.6 \%$ \\
\hline & $11-15$ years & 41 & $19.7 \%$ \\
\hline & Over 15 years & 121 & $58.2 \%$ \\
\hline \multirow{5}{*}{$\begin{array}{l}\text { Level of } \\
\text { Education }\end{array}$} & $\begin{array}{l}\text { Elementary School } \\
\text { (Included) or Below }\end{array}$ & 3 & $1.4 \%$ \\
\hline & Junior High School & 19 & $9.1 \%$ \\
\hline & $\begin{array}{c}\text { Senior High } \\
\text { School/Vocational } \\
\text { School }\end{array}$ & 94 & $45.2 \%$ \\
\hline & College & 81 & $38.9 \%$ \\
\hline & $\begin{array}{l}\text { Graduate School } \\
\text { (included) or Above }\end{array}$ & 11 & $5.3 \%$ \\
\hline
\end{tabular}

(CR) of a latent variable, it is used to measure internal consistency. The suggested value of above 0.6 is reached, since the $\mathrm{CR}$ of latent variables in this study ranges from 0.75 to 0.81 (Fornell \& Lacker, 1981). The variance extracted (VE) of latent variables is used to calculate the average variance explanatory power against each measurement of latent variables. As the VE of this research ranges from 0.51 and 0.58 , the requirement for a suggested value of above 0.5 is met (Fornell \& Lacker, 1981). These three indices indicate that the reliability and validity of this research are excellent. Refer to Table 2 for reliability and validity values.

\section{Goodness-of-Fit Measurement}

The total number of valid samples in this study was identified to be 208, and the Q-plot slope is in compliance with the normal hypothesis. Besides, the core of this research is to build a Sense of Community/Social Capital/Self-rated Health model, such that the demographic variables are analyzed, in which gender, age and educational backgrounds are still correlated to
Sense of Community and Self-rated Health. To obtain the net effects of the model, related demographic variables are under controlled, so that the model may meet the hypothesis. The Chi-square test shows that in the gender section, $\chi^{2}=26.221, p$ $<0.05$ for males, $\chi^{2}=37.233, p<0.05$ for females; in the age section, $\chi^{2}=49.503, p<0.05$ for under 45 years of age, $\chi^{2}=$ $21.943, p<0.05$ for over 46 years of age; in the education section, $\chi^{2}=37.162, p<0.05$ for the senior high school (and below) level, $\chi^{2}=33.653, p<0.05$ for the college (and above) level. The different groups of the aforesaid variables are applicable to the model in this research. Consequently, the measurement of each latent variable will be transformed into a structural model based on the research framework, to verify the goodness of fit of the theoretical model. The researcher expects the null model $\left(\mathrm{H}_{0}\right)$, when using the SEM, to verify the goodness of fit. The statistic $\chi^{2}$ will serve as one of the indicators for observing whether or not the model fits the data. However, $\chi^{2}$ is easily affected by the sample size. To eliminate the impact of sample size upon SEM, the ratio of $\chi^{2}$ to the degree of freedom is usually used to measure the goodness of fit. A value below 3 is required for strict research. In addition, the researcher also needs to consider the important statistical indicators involved provided by SEM (Hair et al., 1998; Jöreskog \& Sörbom, 1996). Seven indicators were selected in this research for evaluation of the overall goodness of fit of the model. Refer to Table 3 for the fit measurements of each indicator.

The $p$-value in this research model meets the suggested value $\left(\chi^{2} / \mathrm{df}=86.72 / 50, p=0.00099\right)$. The other fit indices for the adjusted goodness-of-fit index (AGFI) $=0.90$, Goodness-of-fit index $(\mathrm{GFI})=0.93$, comparative fit index $(\mathrm{CFI})=0.96$, normed fit index $(\mathrm{NFI})=0.92$, and non-normed fit index $(\mathrm{NNFI})=0.95$ are greater than 0.90 , and the root mean square error of approximation $($ RMSEA) $=0.06$ is less than 0.08 . This indicates that the goodness of fit of this research model is excellent.

Table 2.

Variable analysis.

\begin{tabular}{ccccc}
\hline & Mean & Standard Deviation & CR & VE \\
\hline Sense of Community & 3.54 & 0.69 & 0.78 & 0.54 \\
Trust & 3.64 & 0.55 & 0.75 & 0.51 \\
Interaction & 3.42 & 0.70 & 0.81 & 0.58 \\
Self-Rated Health & 3.85 & 0.61 & 0.78 & 0.55 \\
\hline
\end{tabular}

Table 3.

Goodness-of-fit measures for SEM.

\begin{tabular}{ccc}
\hline Fit Indices & Critical Value & Results \\
\hline$\chi^{2} / \mathrm{df}\left(\chi^{2} /\right.$ degrees of freedom) & $<3$ & 1.73 \\
Goodness of fit index (GFI) & $>0.9$ & 0.93 \\
Adjusted goodness of fit index \\
$($ AGFI) & $>0.9$ & 0.90 \\
$\begin{array}{c}\text { Root mean square error of } \\
\text { approximation (RMSEA) } \\
\text { Normed fit index (NFI) }\end{array}$ & $<0.08$ & 0.06 \\
Non-normed fit index (NNFI) & $>0.9$ & 0.92 \\
Comparative fit index (CFI) & $>0.9$ & 0.95 \\
\hline
\end{tabular}




\section{Result of SEM}

Figure 2 shows the relationship between Sense of Community and Trust in Social Capital, with a standardized path coefficient of 0.53 , indicating a higher Sense of Community leading to a higher level of Trust among residents in the community. Accordingly, Hypothesis 1 is established. As for the relationship between Sense of Community and Interaction in Social Capital, the standardized path coefficient is 0.77 , implying a higher Sense of Community causing a higher level of Interaction among the residents in a community. Therefore, Hypothesis 2 is established. For the impact of Social Capital upon Self-rated Health, the dimensions of Trust and Interaction result in standardized path coefficients of 0.22 and 0.64 , respectively, showing a higher level of Trust and Interaction and resulting in a greater level of Self-rated Health. As a result, Hypotheses 3 and $\mathbf{4}$ are established.

\section{Testing of Mediating Effect}

To verify the mediating effect of Social Capital on Sense of Community and Self-rated Health, the method that Williams et al. (2003) operated was adopted by using SEM. Verification includes the establishment of a competing model and a satisfaction of four groups of requirements. The four groups of requirements refer to a significant relationship between independent variables and intervening variables, independent variables and dependent variables and intervening variables and dependent variables. Furthermore, a significant correlation between intervening variables and dependent variables must exist with a stronger effect than independent variables and dependent variables [shown as (a) thru (d) in Figure 3]. For the competing model of the four groups of requirements in Figure 3, only an insignificant relationship between Participation and Self-rated Health in Group 3 exists. The other path requirements are met and the competing model satisfies the requirements of Groups 1 and 2 completely. In Group 4, the original independent variables of Sense of Community vs. Self-rated Health are not significant (path coefficient weakened from 0.62 to 0.11 , compared with the requirements of Group 2). For the original intervening variables, only Participation does not affect Self-rated Health significantly; however, Trust and Interaction are positively significant. As a result, it can be summed up that Social Capital is a critical mediating dimension between Sense of Community and Self-rated Health.

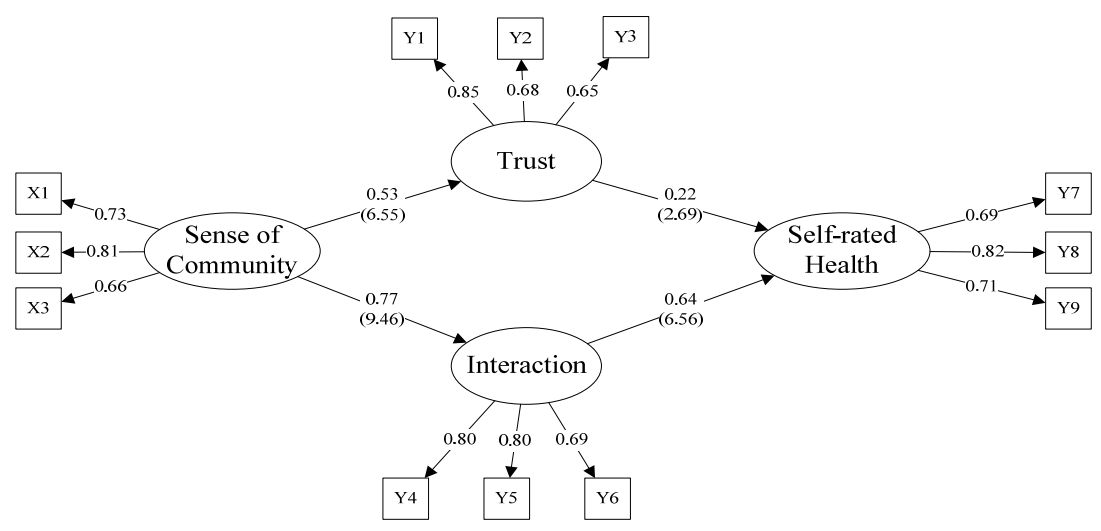

Figure 2.

Result of SEM. Note: ( ) means t-value.

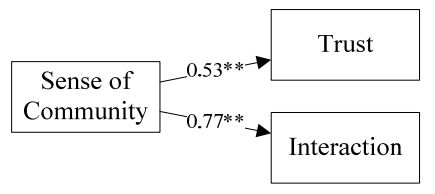

(a) Group 1

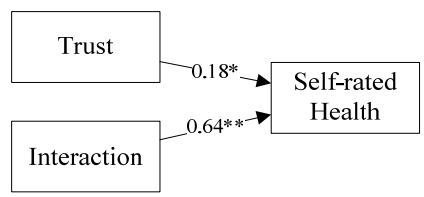

(c) Group 3

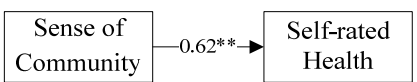

(b) Group 2

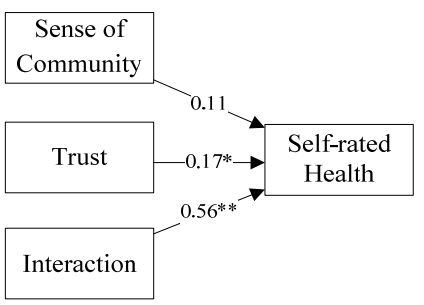

(d) Group 4

Figure 3.

Competing model for sense of community, social capital and self-rated health. Note: ${ }^{*} p<0.05$; ${ }^{* *} p<0.01$ 


\section{Discussion and Conclusion}

According to the t-value of the model, all research hypotheses in this study are within the level of significance as shown in Figure 2, which explains how a significant causality between Sense of Community and Social Capital exists in regards to the two dimensions of Trust and Interaction; nevertheless, a causality is manifested between Social Capital and Self-rated Health with respect to the two dimensions of Trust and Interaction.

The objectives of total community development being promoted in Taiwan currently are to improve interpersonal relationships, to agglomerate a sense of community, and to establish a concept of a living community, which is a movement of creating social capital. A case of X community in Taiwan is studied in this research to prove that sense of community indeed affects self-rated health under the mediating effects of social capital.

\section{The Role of Social Capital as Mediating Factor}

As was mentioned previously, social capital means that an individual has a chance or is qualified to obtain resources in the community network as a member of the community, and that the resources acquired are not personal assets, but public goods contained in a relationship between an individual and others. Putnam (1993) particularly stressed that a social network developed firm principles for general communication and promoted social trust. This type of network helps coordination and communication, enhances identity and belongingness of residents and favors in dealing with predicaments of the community. Hypotheses $\mathbf{1}$ and $\mathbf{2}$ in this research consider that a high level of Sense of Community will result in a high level of Trust and Interaction in Social Capital. A high level of significance is manifested in the model (with t-values of 6.55 and 9.46 respectively). A close causal relationship between Sense of Community and Social Capital is verified once again.

Social capital has been previously defined as those public goods which enhance the living standards of life, including the medical and public operations, to improve the health and livelihood of the community. Ostrom and Ahn (2003) also deemed that the fundamental source of health came from active citizens and a vigorous community, and that social capital may make important contributions to health. In this research, Social Capital has been divided into two parts: Interaction and Trust. A significant causality was manifested for Interaction and Trust in relation to Self-rated Health (t-values of 6.56 and 2.69 respectively) and Interaction was even more significant in particular.

\section{Interaction as a Means to Improve Health}

In addition to families, the interaction formed within a neighborhood is the most basic interpersonal network. Interaction forms in the community are constructed through different dimensions, including the invitation of festivities, caring for sick neighbors and the sharing of resources. The reason why interaction plays the most important role in self-rated health is because a high level of interaction symbolizes a close social network during the process, implying that good interpersonal relationships may efficiently increase cognition of self-rated health (Kawachi, 1999).

\section{Trust as a Means to Improve Health}

Trust is one of the issues that have been discussed most among studies on social capital (Fukuyama, 1995). For the correlation between social capital and community health, trust established between community health promoters and local residents helps the latter accept suggestions for health promotion more easily. The community network of trust also provides opportunities of obtaining health education or information for residents (Sundquist \& Yang, 2007). The interactive network is established by community health promoters, organizations, and by the willingness and active participation of residents. It was found in this study that the items in the Trust dimension with a score of more than 3 on average (no distrust in the community) account for $78.4 \%$, which shows a high level of Trust in the community. A significant correlation between Trust and Selfrated Health also adequately proves the critical influence of Trust on Self-rated Health in the neighborhood. In other words, social capital-firstly through trust, and secondly through social networking - is tremendously beneficial to promote a healthy lifestyle, conduct and practice (Veenstra, 2000).

\section{Research Implications}

The contribution of this research is to present individual interaction by exercising social capital from the aspect of a community. A positive health promotion path is also accepted in a network or members of a community. How to use social resources for more action results for individuals is emphasized, and the collective attributes of the elements of social capital, including trust and interaction in a neighborhood network are the focus.

For an analysis of the application of social capital, the predicaments of a logical circular argument and repetitive meaning are avoided, since Putnam (2001) and Coleman (1990) started social capital with results, in which causes are also the results, if only stock of social capital is used as a characteristic of a community. In addition, this research may serve as a reference of future research designs on specific issues of healthy behavior or habits (e.g. smoking, cancer prevention and exercise, etc.) by applying the basic self-health cognitive appraisals made by the residents at the beginning of developing a community-health promotion model.

\section{Limitations and Suggestions for Further Research}

Finally, there are certain limitations to the design of this research. Although the researcher referred to the research designs of related literature for a Self-rated Health assessment; however, the correlation of mortality rate was also incorporated upon Sundquist and Yang's (2007) advice, to prevent the errors derived from the subjective statements of the respondents. Furthermore, Hill suggested that a long-term observational study on a specified area should be conducted for a true understanding of the impact of Sense of Community upon the happiness perceived by individuals (Hill, 1996). It goes without saying that the testing of an urban- and rural-based operation mode will be essential for different communities in the future (Hyyppä \& Mäki, 2001).

\section{REFERENCES}

Adams, R. E. (1992). Is happiness a home in the suburbs? The influence of urban versus suburban neighborhoods on psychological health. Journal of Community Psychology, 20, 353-371. 
doi:10.1002/1520-6629(199210)20:4<353::AID-JCOP2290200409> 3.0.CO;2-Z

Caspi, A., Taylor, A., Moffitt, T. E., \& Plomin, R. (2000). Neighborhood deprivation affects children's mental health: Environmental risks identified in a genetic design. Psychological Science, 11, 338342. doi:10.1111/1467-9280.00267

Coleman, J. S. (1990). Foundations of social theory. Cambridge: Harvard University Press.

Cutrona, C. E., Russell, D. W., Hessling, R. M., Brown, P. A., \& Murry, V. (2000). Direct and moderating effects of community context on the psychological well-being of African American women. Journal of Personality and Social Psychology, 79, 1088-1101. doi:10.1037/0022-3514.79.6.1088

Davidson, W. B., \& Cotter, P. R. (1993). Psychological sense of community and support for public school taxes. American Journal of Community Psychology, 21, 59-66. doi:10.1007/BF00938207

Davis, F. D. (1993). User acceptance of information technology: System characteristics, user perceptions and behavioral impacts. International Journal of Man-Machine Studies, 38, 475-487.

doi:10.1006/imms.1993.1022

Ding, L., Velicer, W., \& Harlow, L. (1995). Effect of estimation methods, number of indicators per factor and improper solutions on structural equation modeling fit indices. Structural Equation Modeling, 2, 119-143. doi:10.1080/10705519509540000

Duffy K. G., \& Wong, F. Y. (1996). Community psychology. Boston, MA: Allyn Bacon.

Farrell, S. J., Aubry, T., \& Coulombe, D. (2004). Neighborhoods and neighbors: Do they contribute to personal well-being? Journal of Community Psychology, 32, 9-25. doi:10.1002/jcop.10082

Fornell, C., \& Larcker, D. F. (1981). Evaluating structural equation models with unobservable and measurement error. Journal of Marketing Research, 18, 39-50. doi:10.2307/3151312

Fukuyama, F. (1995). Trust: The social virtues and the creation of prosperity. New York: The Free Press.

Hair, J. F., Anderson, R. E., Tatham, R. L., \& Black, W. C. (1998). Multivariate data analysis. New York: Macmillan.

Hill, J. L. (1996). Psychological sense of community: Suggestions for future research. Journal of Community Psychology, 24, 431-438. doi:10.1002/(SICI)1520-6629(199610)24:4<431::AID-JCOP10>3.0. $\mathrm{CO} ; 2-\mathrm{T}$

Hughey, J., Speer, P. W., \& Peterson, N. A. (1999). Sense of community in community organizations: Structure and evidence of validity. Journal of Community Psychology, 27, 97-113.

doi:10.1002/(SICI) 1520-6629(199901)27:1<97::AID-JCOP7>3.0.C $\underline{\mathrm{O} ; 2-\mathrm{K}}$

Hyурpä, M., \& Mäki, J. (2001). Individual-level relationships between social capital and self-rated health in a bilingual community. Preventive Medicine, 32, 148-155. doi:10.1006/pmed.2000.0782

Jöreskog, K. G., \& Sörbom, D. (1996). LISREL8: User's reference guide. Mooresville: Scientific Software.

Kawachi, I., Kennedy, B. P., \& Glass, R. (1999). Social capital and self-rated health: A contextual analysis. American Journal of Public Health, 89, 1187-1193. doi:10.2105/AJPH.89.8.1187

Marsh, H. W., Balla, J. R., \& McDonald, R. P. (1988). Goodness-of-fit indices in confirmatory factor analysis: The effect of sample size. Psychological Bulletin, 103, 391-410.

doi:10.1037/0033-2909.103.3.391

Mcknight, J. (2002). Two tools for well-being: Health systems and communities. In M. Minkler (Ed.), Community Organizing and Community Building for Health. New Bninswick: Rutgers University Press.

McMillan, D. W., \& Chavis, D. M. (1986). Sense of community: A definition and theory. Journal of Community Psychology, 14, 6-23. doi:10.1002/1520-6629(198601)14:1<6::AID-JCOP2290140103>3.0 . $\mathrm{CO} ; 2-\mathrm{I}$
Onyx, J., \& Bullen, P. (2000). Measuring social capital in five communities. Journal of Applied Behavioral Science, 36, 23-42. doi: $10.1177 / 0021886300361002$

Ostrom, E., \& Ahn, T. K. (2003). Foundations of social capital. Cheltenham, UK: Edward Elgar.

Patrick, D. L., \& Erickson, P. (1993). Health status and health policy: Quality of life in health care evaluation and resource allocation. New York: Oxford University Press.

Peterson, N. A., Speer, P. W., \& Hughey, J. (2006). Measuring sense of community: A methodological interpretation of the factor structure debate. Journal of Community Psychology, 34, 453-469. doi:10.1002/jcop.20109

Pooley, J. A., Cohen, L., \& Pike, L. T. (2005). Can sense of community inform social capital? The Social Science Journal, 42, 71-79. doi:10.1016/j.soscij.2004.11.006

Prezza, M., Amici, M., Roberti, T., \& Tedeschi, G. (2001). Sense of community referred to the whole town: its relations with neighboring, loneliness, life satisfaction and area of residence. Journal of Community Psychology, 29, 29-52. doi:10.1002/1520-6629(200101)29:1<29::AID-JCOP3>3.0.CO;2-C

Prezza, M., \& Costantini, S. (1998). Sense of community and life satisfaction: Investigation in three different territorial contexts. Journal of Community \& Applied Social Psychology, 8, 181-194.

doi:10.1002/(SICI)1099-1298(199805/06)8:3<181::AID-CASP436> 3.0.CO;2-4

Protes, A. (1998). Social capital: Its origins and applications in modern sociology. Annual Review of Sociology, 24, 1-24. doi:10.1146/annurev.soc.24.1.1

Putnam, R. D. (1993). Making democracy work: Civic traditions in modern Italy. Princeton, NJ: Princeton University Press.

Putnam, R. D. (2000). Bowling alone: The collapse and revival of American community. New York: Simon \& Schuster.

Putnam, R. D. (2001). Social capital: Measurement and consequences. Canadian Journal of Policy Research, 2, 41-51.

Reilly, T. (1995). A necessary and sufficient identification of confirmatory factor analysis models of complexity one. Sociological Methods \& Research, 23, 421-441. doi:10.1177/0049124195023004002

Rigdon, E. E. (1995). A necessary and sufficient identification rule for structural models estimated in practice. Multivariate Behavioral Research, 30, 359-383. doi:10.1207/s15327906mbr3003 _

Sarason, S. B. (1974). The psychological sense of community: Prospects for a community psychology. San Francisco: Jossey-Bass.

Sundquist, K., \& Yang, M. (2007). Linking social capital and self-rated health: a multilevel analysis of 11,175 men and women in Sweden. Health Place, 13, 324-334. doi:10.1016/j.healthplace.2006.02.002

Tanaka, J. (1987). How big is enough? Sample size and goodness-of-fit in structural equation models with latent variables. Child Development, 58, 134-146. doi:10.2307/1130296

Ullman, J. B. (2001). Structural equation modeling. In: B. G. Tabachnick, \& L. S. Fidell (Eds.), Using multivariate statistics. Boston, MA: Pearson Education.

Veenstra, G. (2000). Social capital, SES and health: An individual-level analysis. Social Science \& Medicine, 50, 619-629. doi:10.1016/S0277-9536(99)00307-X

WHO (1981). Global strategy for all by the year 2000. Geneva: WHO.

Williams, L. J., Edwards, J. R., \& Vandenberg, R. J. (2003). Recent advances in causal modeling methods for organizational and management research. Journal of Management, 29, 903-936.

Wilson, G., \& Baldassare, M. (1996). Overall "sense of community" in a suburban region: The effects of localism, privacy, and urbanization. Environment and Behavior, 28, 27-43. doi: $10.1177 / 0013916596281002$

Yan, J. (2006). Investing in social capital: A new dimension for political development. Beijing: Peking University Press. 